\title{
First Modi budget spells austerity for Indian science
}

Funding drops in real terms, but researchers hopeful things will improve.

\section{K. S. Jayaraman}

11 July 2014

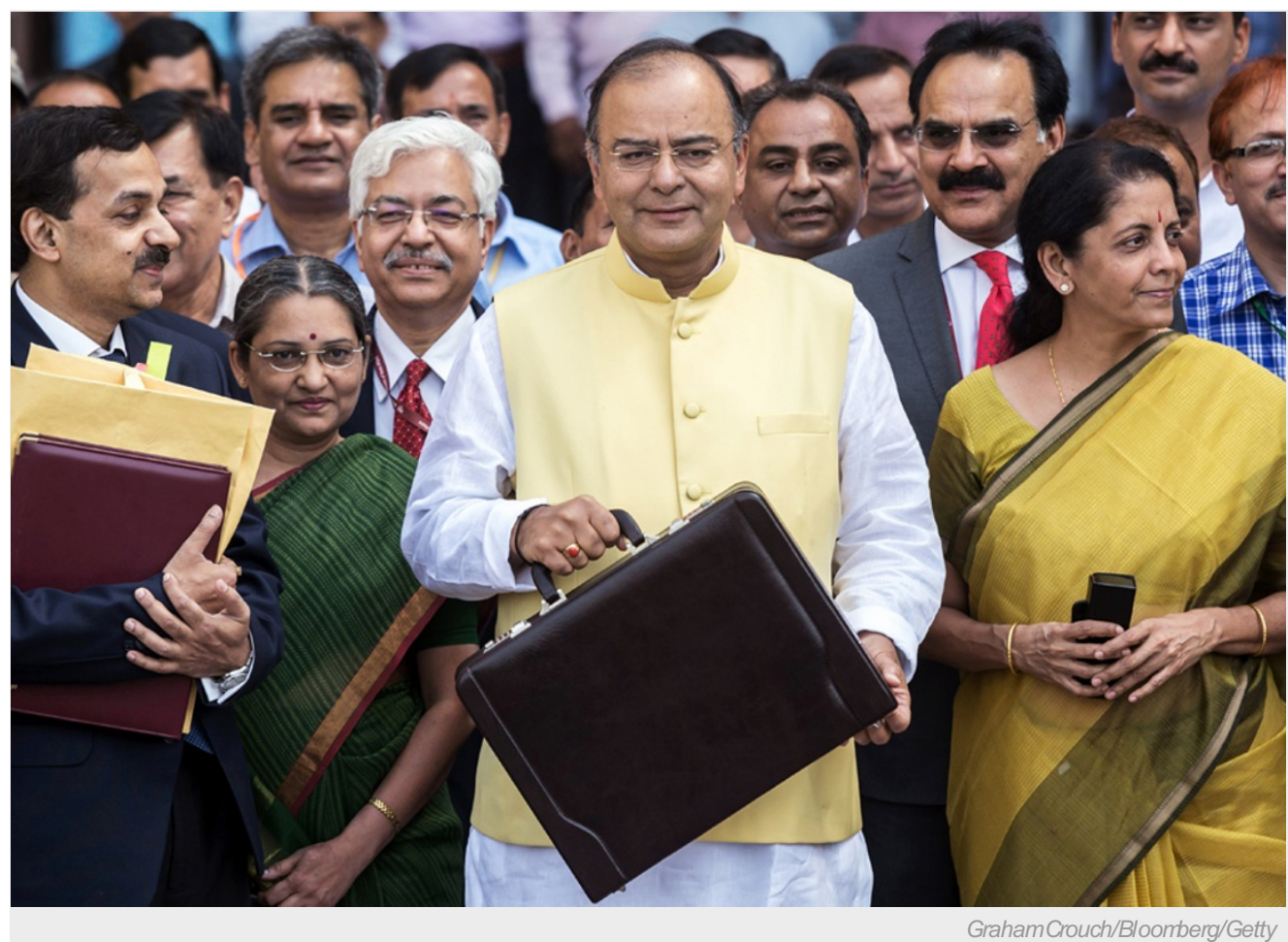

Indian finance minister Arun Jaitely (centre) presented the government's 2014-15 budget on 10 July.

The Indian government's first budget has not delivered the good days, or achhe din, promised by new prime minister Narendra Modi. A below-inflation funding increase has disappointed scientists, but many are optimistic that the government will come up with the funds eventually.

Finance minister Arun Jaitely presented the 2014-15 budget on 10 July, just 45 days after the formation of the government. He tempered expectations by saying that it would be wise not to expect much in the face of a two-year slowdown in the Indian economy. And indeed, research received 362.69 billion rupees (US\$6.04 billion): a 4\% increase over last year, compared with inflation of $8 \%$ (see 'Budget allocations').

The Department of Science and Technology (DST) has been given 35.44 billion rupees — an 11\% jump — but other ministries have fared less well. For example, the allocation for the Department of Biotechnology has risen by just $0.9 \%$, at 15.17 billion rupees. Space and atomic energy each saw roughly a $6 \%$ rise in this year's budget.

Budget allocations (millions of rupees)
\begin{tabular}{|l|l|l|}
\hline & $\mathbf{2 0 1 3 - 1 4}$ & $\mathbf{2 0 1 4 - 1 5}$ \\
\hline Department of Atomic Energy & 98,330 & 104,460 \\
Department of Health Research & 10,080 & 10,177 \\
Department of Science and Technology & 31,843 & 35,440 \\
Department of Scientific and Industrial Research & 35,710 & 37,072 \\
Department of Biotechnology & 15,020 & 15,172 \\
Department of Space & 67,920 & 72,380 \\
\hline Department of Agricultural Research and Education & 57,290 & 61,440 \\
\hline
\end{tabular}




\begin{tabular}{|l|l|l|}
\hline & $\mathbf{2 0 1 3 - 1 4}$ & $\mathbf{2 0 1 4 - 1 5}$ \\
\hline Ministry of Earth Sciences & 16,900 & 16,990 \\
\hline Ministry of New and Renewable Energy & 15,340 & 9,560 \\
\hline All numbers are from the ministry-approved budget. & \\
\hline
\end{tabular}

\section{Inadequate funding}

"I was expecting much more from the Modi government," says C. N. R. Rao, who was head of the Scientific Advisory Council to former prime minister Manmohan Singh. Rao has repeatedly blamed poor performance by Indian scientists on "inadequate" funding. "I'm upset that no new national mission has been announced for energy or water management," he told Nature.

"The budget does not present any exciting new possibilities for education in general and for science and technology in particular," says Subhash Lakhotia, a biologist at Banaras Hindu University in Varanasi.

However, Jaitely did announce funding for two new agricultural-biotechnology research hubs; a national centre for Himalayan studies; huge solar-power plants; and canal-side solar parks that will each produce 1 megawatt of electricity.

He also announced cash to set up five new research and education centres in the Indian Institutes of Technology (IITs) group, five new Indian Institutes of Management (IIMs) and four institutions similar to the All India Institute of Medical Sciences in New Delhi.

Rao is sceptical. "Existing IITs are in bad shape and they need strengthening instead of creating new ones," he says.

Lakhotia agrees: "Hundreds of existing universities and colleges are languishing in the absence of resources and material, as well as good faculty."

\section{International collaborations}

The frugal spending this year is raising doubts over the fate of several big-money projects that were earlier approved by the government's Planning Commission but are awaiting funding from the DST and the Department of Atomic Energy.

These include a 4.6-billion-rupee supercomputer facility, a 13.24-billion-rupee underground India-based Neutrino Observatory (INO), the US $\$ 250$-million Laser Interferometer Gravitational-Wave Observatory to be set up as an Indo-US venture, and the Indian Synchrotron for Materials and Energy Research, which is estimated to cost 7 billion rupees.

In addition, India is expected to provide funds for its part in international science collaborations including the Thirty Metre Telescope on Mauna Kea in Hawaii; the Square Kilometre Array radio telescope in Australia and South Africa; and the Facility for Antiproton and lon Research near Darmstadt, Germany.

But despite budget concerns, many in the science community remain hopeful. Krishnaswamy VijayRaghavan, secretary of the DST, says that people should not worry about a budget prepared "under difficult circumstances". The figures will be revised in September when departments make their mid-term revisions of requirements, and more money will be found, he says. "After all, these programmes are spread over time. I am optimistic."

Naba Kumar Mondal, spokesperson for the INO project, agrees: "I expect a breakthrough by September."

And Narayanaswami Balakrishnan, who heads the supercomputer project at the Indian Institute of Science in Bangalore, is also stoical. "There will be a delay, but our project will come through," he says.

Nature | doi:10.1038/nature.2014.15542 